\title{
Mathematical Modeling of Technological Modes of Operation of Liquid Stamping of Aluminum Alloy AK7
}

\author{
Vagid Kadymov $^{1}$, Evgeny Sosenushkin ${ }^{2}$ \\ ${ }^{1}$ Russian Technological University- MIREA, RU-119484, Moscow, Russia \\ ${ }^{2}$ Moscow State Technological University "STANKIN", RU-127055, Moscow, Russia
}

\begin{abstract}
In this paper we examine a mathematical model of solidification of the melt in a two-phase zone during the formation of forgings through liquid stamping. From the simultaneous solution of the Fourier equations of thermal conductivity for the melt, the two-phase zone, and the solid crust, the solidification kinetics has been established and the effect of external pressure on the temperature fields and components of the solidification time of hollow thin-walled forgings has been thoroughly assessed.
\end{abstract}

\section{Introduction}

The technology of forming of crystallized metal (liquid stamping) successfully competes with the processes of casting [1] and metal processing by pressure [2] in the hot state in closed dies [3, 4]. It is necessary to expand the technological capabilities of metal processing by pressure in the manufacture of products made of hard-todeform alloys and metals with low plastic properties. The metal utilization rate increases to 0.95 due to reduced allowances for further machining and the absence of Gating systems [5] and the deformation forces are reduced by 3-5 times when the technology is implemented. The metal of forgings acquires a finegrained structure, and the physical and mechanical properties of products that are produced by stamping of crystallized metal increase by $15-20 \%$ [6-8]. All these trends are determined by the technological parameters of the liquid stamping process, which include, in particular, the deformation force, temperature intervals for pouring molten metal into the die cavity, the temperature of the die elements themselves, as well as the time of filling the die cavity and crystallization, the value of which is of particular importance when stamping thin-walled forgings. The term "thin-walled" is used in relation to hollow forgings, of which the wall thickness is less than one-tenth of the maximum forging size or less than onetenth of the diameter in case of axisymmetric forgings. The formation of the forging structure depends on the external pressure, the intensity of heat exchange with the tool and the environment [9]. Modeling of heat exchange conditions allows us to estimate the thermal fields of contacting bodies, as well as the duration of the cooling stages of forgings [10-12]. However, it is necessary to draw attention to the problems, associated with this type of forming technology, among which the durability of the die tool $[13,14]$ remains one of the most important problems.

\section{Problem formulation}

To describe the modeling of heat exchange processes during solidification at the boundary of two contiguous bodies, we use the Fourier equation of thermal conductivity and the one-valuedness conditions that characterize the phenomenon of heat propagation under study. The geometric parameters and physical characteristics of contacting bodies are usually known from the problem statement. Time conditions are defined as temperature distribution in the bodies for a specific point of time. For example, at the initial point of time, the temperature is distributed evenly in the body, meaning if $\mathrm{t}=0, \mathrm{~T}=\mathrm{T} 0$.

In the real technological process of crystallization under pressure, the liquid metal contacts the surface of the die, so as a boundary condition, thus we will use the condition of equality of heat fluxes on the surface of contact of the liquid phase of the crystallizing alloy with the die material:

$$
-\lambda\left(\frac{\partial T}{\partial n}\right)_{n}=\alpha\left(T_{n}-T_{C}\right)
$$

where $\lambda$ is the thermal conductivity of the melt, $\mathrm{W} /(\mathrm{m} \times \mathrm{K}) ; \alpha$ is the coefficient of heat transfer by contact,

$\mathrm{W} /(\mathrm{m} 2 \times \mathrm{K}) . \quad\left(\frac{\partial T}{\partial n}\right)_{n}$ is temperature gradient on the contact surface, $\mathrm{K} / \mathrm{m}$; Tn, Tc - temperatures of the contact surface and the medium, respectively, $\mathrm{K}$. The diagram of process of hardening of metal of hollow forgings in the two-phase zone is shown in Fig. 1. 


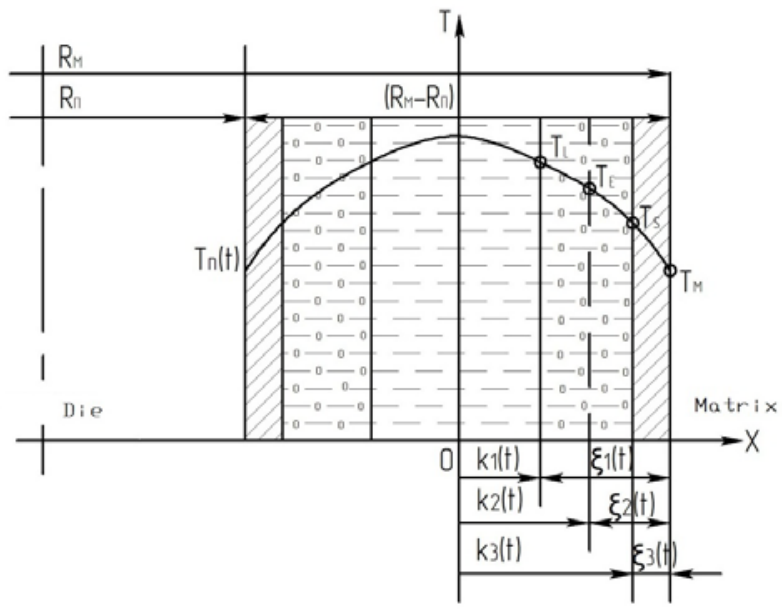

Fig. 1. The process of solidification of a hollow forging in the two-phase zone:

temperature fields: TL - liquidus temperature; TE - the temperature of the conventional solidification front; TS solidus temperature; $\mathrm{T} n(-\mathrm{x}, \mathrm{t})=\mathrm{T} \mathrm{m}(\mathrm{x}, \mathrm{t})=\mathrm{T} \omega(\mathrm{t})$ is the temperature of the punch and die matrix; geometric parameters: Rм, Rп the radii of the die and punch; $s=\mathrm{Rm}-\mathrm{R} \Pi$ - the thickness of the forging wall; $\xi(\mathrm{t})$ - the thickness of the solid crust; k1(t), k3(t) - the coordinates of the fronts of the beginning and the end of crystallization; $\mathrm{k} 2(\mathrm{t})$ - the coordinate of the conditional crystallization front.

The technological process of forming the forgings with melt crystallization under pressure consists of the following stages:

- melting of the alloy in an electric furnace at the temperature of the furnace Тп, K;

- pouring into the die a portion of the melt with a volume of $\mathrm{V}(\mathrm{m} 3)$ at a temperature of Тзал (K) during $\mathrm{t}$ (s);

- removal of the heat of overheating $\mathrm{T}(\mathrm{K})$ for the time $\mathrm{t} 1$ (s);

- solidification of the forging in the range of liquidus and solidus temperatures [TL, TS] at the crystallization temperature Ткр, (К) under external pressure p, MPa during the removal of the latent heat of crystallization t2 (s);

- cooling of the forging in the die cavity and subsequent ejection.

Let's establish a system of differential equations that describe the heat exchange between the forging and the die during solidification.

For superheated melt in the non-solidified part of the forging

$$
\frac{\partial T_{1}}{\partial t}=a_{1} \frac{\partial^{2} T_{1}}{\partial x^{2}} ; 0<x<k_{1}(t)
$$

\section{Equations and mathematics}

To mathematically describe the processes occurring in a two-phase zone, we can use the heat conduction equation in general form, taking into account the heat release from internal sources distributed over the volume [2]: $c_{2} \gamma_{2} \frac{\partial T_{2}}{\partial t}=\lambda_{2} \frac{\partial^{2} T_{2}}{\partial x^{2}}+L \gamma_{2} \frac{\partial \psi}{\partial t} ; k_{1}(t)<x<k_{2}(t)$.

The relative amount of solid phase, crystallizing in the two-phase forging zone, is characterized by the function $\psi$, which is defined as a function of temperature, and the rate of formation of the solid phase is as follows:

$$
\frac{\partial \psi}{\partial t}=\frac{\partial \psi}{\partial T} \cdot \frac{\partial T}{\partial t}=\mu \frac{\partial T}{\partial t}
$$

where $\mu=\frac{\partial \psi}{\partial T}$ is the rate of crystallization of the alloy within the temperature range [TL, TS]. If taken as a function $\psi=\sqrt{x t}$, its partial time derivative is defined as $\frac{\partial \psi}{\partial t}=\frac{1}{2} \frac{\sqrt{x}}{\sqrt{t}}$. The simplest accounting for the fraction of the solid phase $\psi\left(T_{2}\right)$ during crystallization in the two-phase zone

$$
\psi\left(T_{2}\right)=\frac{T_{L}-T_{2}}{T_{L}-T_{S}}
$$

For a hard crust

$$
\frac{\partial T_{3}}{\partial t}=a_{3} \frac{\partial^{2} T_{3}}{\partial x^{2}} \quad k_{3}(t)<x<\frac{s}{2}
$$

The conditions of equality of heat fluxes at the front of the beginning of crystallization

$$
-\lambda_{1} \frac{\partial T_{1}\left(k_{1}, t\right)}{\partial x}=-\lambda_{2} \frac{\partial T_{2}\left(k_{1}, t\right)}{\partial x}
$$

at the front of the end of crystallization in the two-phase zone

$$
-\lambda_{2} \frac{\partial T_{2}\left(k_{2}, t\right)}{\partial x}=-\lambda_{3} \frac{\partial T_{3}\left(k_{1}, t\right)}{\partial x}
$$

Boundary conditions:

$$
\begin{aligned}
& T_{1}\left(k_{1}, t\right)=T_{2}\left(k_{1}, t\right)=T_{L} \\
& T_{2}\left(k_{2}, t\right)=T_{3}\left(k_{2}, t\right)=T_{S}
\end{aligned}
$$

To account for physical processes in the two-phase zone within the alloy crystallization interval let us choose the temperature $T_{E}=\frac{1}{2}\left(T_{L}-T_{S}\right)$ and assume that the crystallization process is almost complete in the twophase zone by the time this temperature is reached. In this case, the solidification kinetics is characterized by 
the growth rate of the solid crust $U(t)=\frac{\partial \xi}{\partial t}$. Therefore, it is possible to replace the condition of equality of heat fluxes at the front of the end of crystallization in the twophase zone with the differential equation of Stefan solidification, and replace the coordinate $\mathrm{k} 3(\mathrm{t})$ with $\mathrm{k} 2(\mathrm{t})$. Then, for a two-phase zone, the differential equation of solidification [2] is defined as follows:

$$
\begin{gathered}
-\lambda_{2} \frac{\partial T_{2}\left(k_{2}, t\right)}{\partial x}+\left[1-\psi\left(k_{2}, t\right)\right] L \gamma_{3} U=-\lambda_{3} \frac{\partial T_{3}\left(k_{2}, t\right)}{\partial x} ; \\
k_{1}(t)<x<k_{2}(t) .
\end{gathered}
$$

The conditions for equality of heat fluxes:

$$
-\lambda_{i} \frac{\partial T_{i}\left(\frac{s}{2}, t\right)}{\partial x}=q_{0}(t) ; \frac{\partial T_{i}(0, t)}{\partial x}=0 \quad ; \mathrm{i}=1 \text { and } 3 \text {; }
$$

or

$$
\begin{gathered}
T_{i}\left(\frac{s}{2}, t\right)=T_{0}(t) \quad \frac{\partial T_{i}(0, t)}{\partial x}=0 ; \mathrm{i}=1 \text { and 3; } \\
k_{2}\left(t_{\text {зал }}\right)=\frac{s}{2} ; \quad T_{1}\left(x, t_{\text {зал }}\right)=T_{E}=\text { const } \\
T_{1}\left(k_{2}, t\right)=T_{3}\left(k_{2}, t\right)=T_{E} .
\end{gathered}
$$

To reduce the intensity of heat exchange between the melt and the die, a layer of technological lubricant is applied to the surface of the die, from which (lubricant) the liquid phase evaporates upon contact with the melt, and its components partially burn out, forming an airgaseous layer. Solid components, such as graphite, settle on the surface of the tool, on which an oxide film is formed at elevated temperatures. As a result, the gap between the forging and the die is filled with layers of these components. The gap in the thermal ratio creates a thermal resistance that is quantified:

$$
R_{\text {заз }}=\frac{X_{\text {заз }}}{\lambda_{\text {заз }}}
$$

where $\mathrm{X}$ заз is the gap thickness, $\mathrm{m}$; $\lambda_{\text {заз }}$ is the effective coefficient of thermal conductivity of the substance filling the gap, $\mathrm{W} /(\mathrm{m} \times \mathrm{K})$. The inverse value of the thermal resistance is called the coefficient of heat transfer through the gap. In a multi-layer gap, this coefficient is equal to:

$$
\beta=\frac{1}{R_{\text {заз }}}=\frac{1}{R_{1}}+\frac{1}{R_{2}}=\ldots=\frac{1}{R_{n}} .
$$

The relatively low heat exchange rate of the melt with the die and the die with the environment makes it possible to ignore the unevenness of the thermal fields in the cross sections of the forging and the die. Under these conditions, it is appropriate to independently consider the characteristic stages of the technological process. The constancy of the thermal resistance of the gap substance and the temperature head for the metal melt in the mobile and stationary state means that the value of the heat flow from the melt into the stamp through the gap remains unchanged in both cases. The flow of metal in the die at the filling stage is expressed in the fact that the stamp is additionally warmed up, and the melt loses some of the heat. The amount of heat that is transferred from the melt to the die through the punch and die matrix during the time $\mathrm{dt}$ is defined as the ratio:

$$
d^{2} Q_{1}=\beta\left(T_{1}-T_{n}\right) d S_{n} d t+\beta\left(T_{1}-T_{M}\right) d S_{m} d t
$$

Change in the heat content of the melt during the same time:

$$
d^{2} Q_{2}=-c_{1} \gamma_{1} d V d T
$$

where $V=V_{\mu}-V_{n}$-is the forging volume, m3. The heat balance equation is defined as:

$$
\begin{aligned}
& \beta\left(T_{1}-T_{n}\right) d S_{n} d t+\beta\left(T_{1}-T_{M}\right) d S_{M} d t= \\
& =-C_{1} \gamma_{1}\left(d V_{M}-d V_{n}\right) d T
\end{aligned}
$$

Let us solve it with respect to time dt:

$$
d t=-\frac{1}{\beta} \frac{c_{1} \gamma_{1}\left(d V_{\mu}-d V_{n}\right) d T}{T_{1}\left(d S_{n}+d S_{M}\right)-\left(T_{n} d S_{n}+T_{M} d S_{\mu}\right)} .
$$

After integration we obtain:

$$
\begin{aligned}
& t=-\frac{1}{\beta} \frac{c_{1} \gamma_{1}\left(d V_{M}-d V_{n}\right)}{\left(d S_{n}+d S_{M}\right)} . \\
& \cdot \ln \left|\left(T_{1}-T_{n}\right) d S_{n}+\left(T_{1}-T_{M}\right) d S_{M}\right|+C,
\end{aligned}
$$

where the value $C$ is the integration constant, which is excluded under the condition $\mathrm{t}=0$

$$
\begin{gathered}
\ln \left|\left(T_{1}-T_{n}\right) d S_{n}+\left(T_{1}-T_{\mu}\right) d S_{\mu}\right|=0, \text { thus } \mathrm{C}=0, \\
t=-\frac{1}{\beta} \frac{c_{1} \gamma_{1}\left(d V_{M}-d V_{n}\right)}{\left(d S_{n}+d S_{M}\right)} . \\
\cdot \ln \left|\left(T_{1}-T_{n}\right) d S_{n}+\left(T_{1}-T_{M}\right) d S_{\mu}\right|
\end{gathered}
$$

One of the main parameters when forming a crystallizing metal are the pressure and the duration of its impact on the solidifying metal. First of all, the pressure, applied to the liquid metal during its crystallization, eliminates gas porosity [15]. The release 
of gases from the metal during crystallization occurs due to the lower solubility of gases in the solid metal compared to its liquid state. Practice shows that the decrease in porosity occurs to a much greater extent than it would occur according to the Boyle-Mariotte law. The fact is that in addition to the compressing effect of pressure on the gas porosity, the pressure also increases the solubility of gases in the liquid metal, which leads to a decrease in the amount of gas released from the metal when it solidifies. Liquid metal under the influence of pressure during deformation solidifies much faster than when casting in a metal mold without applying pressure. This phenomenon is explained in terms of thermodynamics of the process. For a two-phase thermodynamically equilibrium system, temperature is a function of pressure, and this dependence is expressed by the Clausius-Clapeyron equation [5]:

$$
\frac{d T_{\kappa p}}{d p}=\frac{\Delta V T_{\kappa p}}{L}, \Delta T=\int_{0}^{p} \frac{\Delta V T_{\kappa p}}{L} d p=\frac{\Delta V T_{\kappa p}}{L} p
$$

Next, the melt crystallization temperature is determined depending on the external pressure $\mathrm{p}=100$ $250 \mathrm{MPa}$ :

$$
T_{\kappa p}^{p}=T_{\kappa p}+\frac{\left(V_{1}-V_{3}\right) T_{\kappa p}}{L} p
$$

where V3 is the volume of forging in the solid state, m3. The temperature of pouring the melt into the die depends on the temperature range of metal solidification. The wider the range, the lower can be the temperature of pouring the melt, as a part of the solution to the equation of solidification, and that is usually the minimum for the particular conditions of cooling during filling of the die, but greater than the metal crystallization temperature. Therefore, the calculation is carried out in accordance with the formula proposed by A.I. Veynik [1]:

$$
T_{\text {зал. }}=T_{\kappa p}^{p}+\frac{\left(T_{\kappa p}^{p}-T_{4}\right) b_{4}}{b_{1}},
$$

where $b_{i}=\sqrt{\lambda_{i} c_{i} \gamma_{i}}$ - coefficient of heat accumulation $(i=1,4)$ : for die, index $i=4$.

Relative pour temperature is defined as follows:

$$
\theta_{\text {зал }}=\frac{T_{\text {зал }}-T_{4}}{T_{L}-T_{4}}
$$

Now the time when a portion of the melt is poured into the die can be defined [2]:

$$
t_{\text {зал }}=\left[\frac{c_{1} \gamma_{1}\left(\theta_{\text {зал }}-1\right)}{1,13 b_{4} \theta_{\text {зал }}}\right]^{2} R_{n p}^{2},
$$

$$
T_{\text {nep }}=T_{\text {зал }}-T_{\kappa p}^{p} .
$$

Temperature head is:

$$
\Delta T=T_{\text {зал }}-T_{4} .
$$

The time of superheat removal is found from equation (17), taking into account the known volumes and contact areas, which, when decomposing the function $y=\ln (x)$ into a Maclaurin series, takes the form:

$$
t_{1}=\frac{R_{n p} \xi(T) C_{1} \gamma_{1}}{\lambda_{1}} \frac{T_{n e p}}{\Delta T}
$$

where $R_{n p}=\frac{V}{S_{n}+S_{m}}$ is the reduced forging radius, $m$. The temperature on the surface of the die in contact with the melt can be found [16]:

$$
T_{\kappa}=\frac{T_{\text {зал }} b_{1}+T_{4} b_{4}}{b_{1}+b_{4}},
$$

and when a solid crust is formed with a thickness of $\xi(t)$, the temperature of its contact with the die can be found by analogy:

$$
T_{\kappa}=\frac{T_{\kappa p}^{p} b_{3}+T_{4} b_{4}}{b_{3}+b_{4}}
$$

The height of the melt rise in the die channel depends on the fill temperature, die temperature, slider movement speed, and channel geometry [17]. For axisymmetric forgings in the coordinate system associated with the punch, under the condition of continuity of the jet, the ratio of speeds is obtained:

$$
v_{K}=\frac{R_{M}^{2}}{R_{M}^{2}-R_{\Pi}^{2}} v_{\Pi},
$$

where $v \mathrm{~K}, \mathrm{v} \Pi$ are the speed in the die channel and the speed of the punch respectively; RM, RП - radii of the die matrix and punch.

\section{Results}

The results of modeling the process of solidification of an aluminum alloy in a two-phase zone during liquid stamping of a hollow forging are presented in the form of graphs. Fig. 2 shows the effect of external pressure applied to the meltduring crystallization on the temperature factors.

Melt superheat temperature is: 


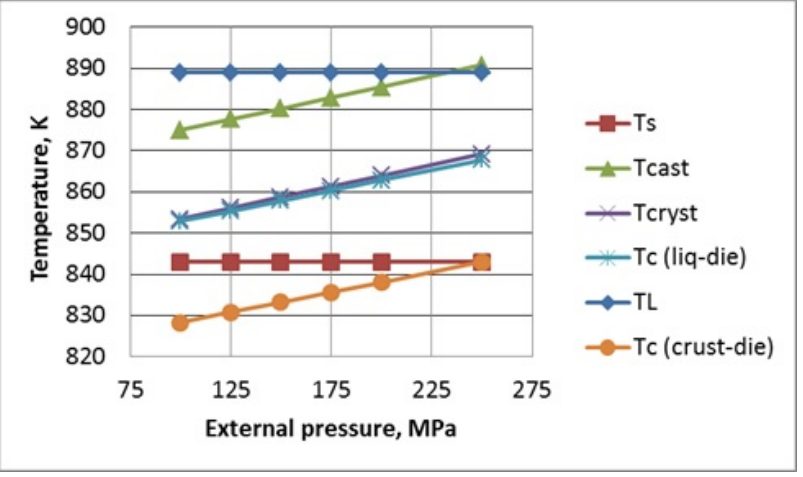

Fig. 2. Dependence of temperature factors on external pressure

Thus, the crystallization temperature is directly dependent on the pressure. The graph shows that as the external pressure developed by the press increases, the crystallization temperature increases. The law of temperature change is linear. Even at low pressures, the crystallization temperature does not cross the solidus line of this alloy, and the superheat temperature varies within small limits-3.01 K. This suggests that under the influence of external pressure, the alloy crystallizes earlier at temperatures above the solidus temperature. This feature is confirmed in the practice of foundry production, which aims at reducing the temperature of overheating in order to avoid hot cracks [1]. So, the temperature of crystallization under pressure becomes higher than the temperature of the melt subjected to deformation. In this case, the entire volume of the melt, which did not have time to solidify before applying pressure, is immediately supercooled relative to the new temperature of the beginning of crystallization, which naturally causes the appearance of crystallization centers in it. The greater the pressure applied to the melt or the lower the temperature of the melt to which the pressure is applied, the greater supercooling will be achieved relative to the new crystallization temperature and the more fine-grained structure will be formed during solidification. The higher the contact surface temperature, the longer it takes to remove the superheat temperature (Fig. 3, a). The superheat temperature also affects the proportion of the solid phase in the two-phase solidification zone. In accordance with the linear law of the change in the fraction of the solid phase depending on the temperature, the nature of this change is shown in Fig. 3, b.

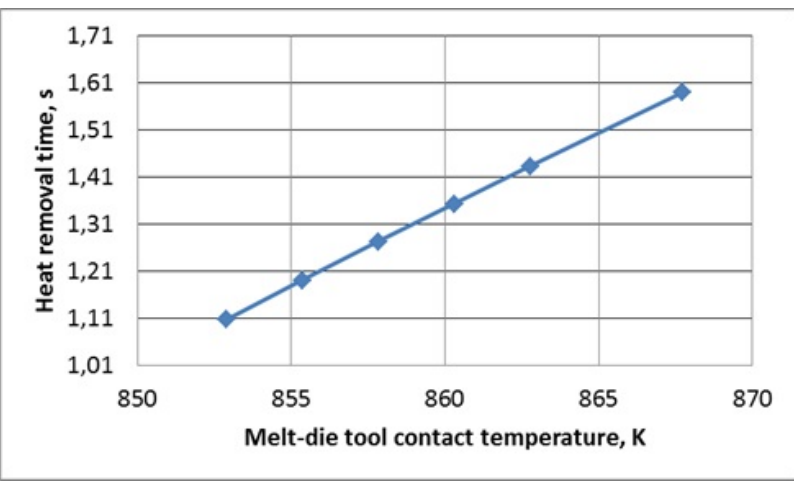

(a)

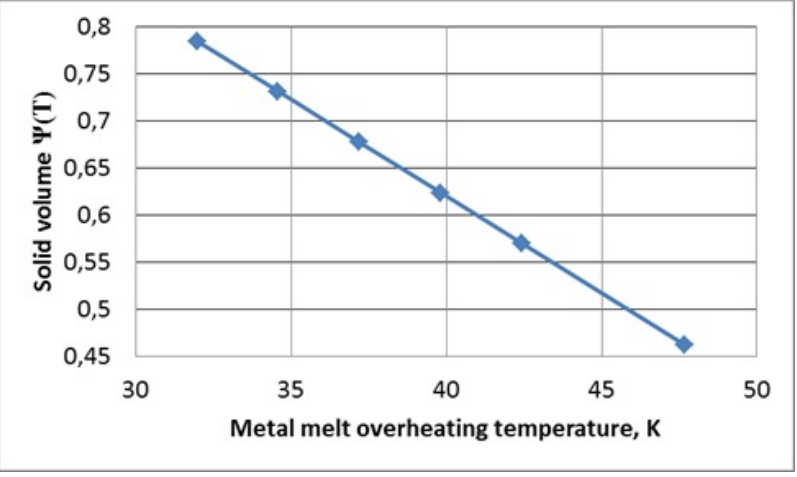

(b)

Fig. 3. Dependence of the superheat temperature removal time (a) on the contact surface temperature and the effect of the melt superheat temperature on the solid phase fraction during solidification in the temperature range (b).

With a decrease in the superheating temperature, the proportion of the solid phase in the two-phase solidification zone increases, which does not contradict the physics of the process. The graphs in Fig. 4 revealed the influence of the preheating temperature of the die on the temperature parameters of the melt. After pouring the melt and starting the deformation process, part of the heat passes into the die, the melt is supercooled and its temperature drops to the value of the crystallization temperature. Therefore, as the graph shows, the temperature on the contact surface is not much different from the crystallization temperature.

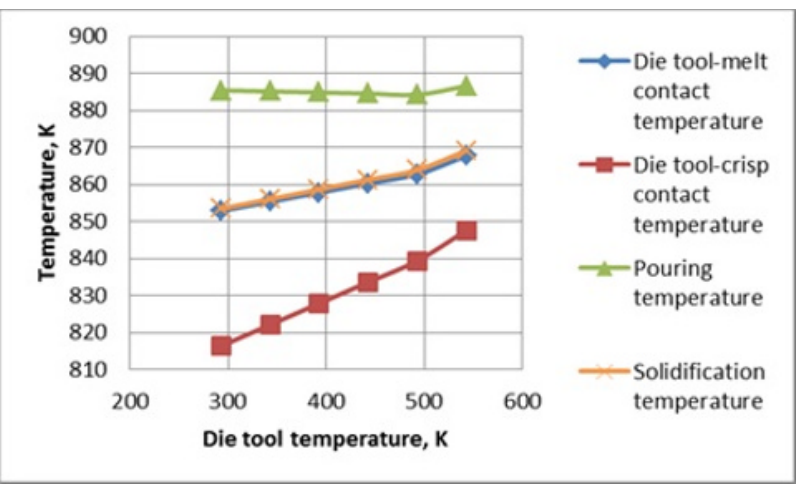

Fig. 4. Dependence of temperature fields on the die temperature

Since the forging material is constantly in contact with the die surface, part of the metal crystallizes to form a solid crust with a thickness of $\xi(t)$, the heat exchange conditions change and the temperature on the contact surface decreases (see Fig. 4).

An important point that affects the quality of forging is filling of the die cavity with melt until it is completely solidified. The higher the pouring (filling) temperature, the more time it takes to remove the superheat temperature. You can control the process of filling of the die by adjusting the speed of the press slider. Low-speed hydraulic presses are usually used for the implementation of the liquid stamping process, which ensure that the slider stands without pressure relief. According to the graphs in Fig. 5 you can select the temperature of the melt pouring into the die and the 
speed of movement of the press slider to ensure the flow of the melt in the gap between the punch and the matrix, with a guaranteed rise to the desired height equal to the height of the wall of the thin-walled hollow forging until it is completely solidified.

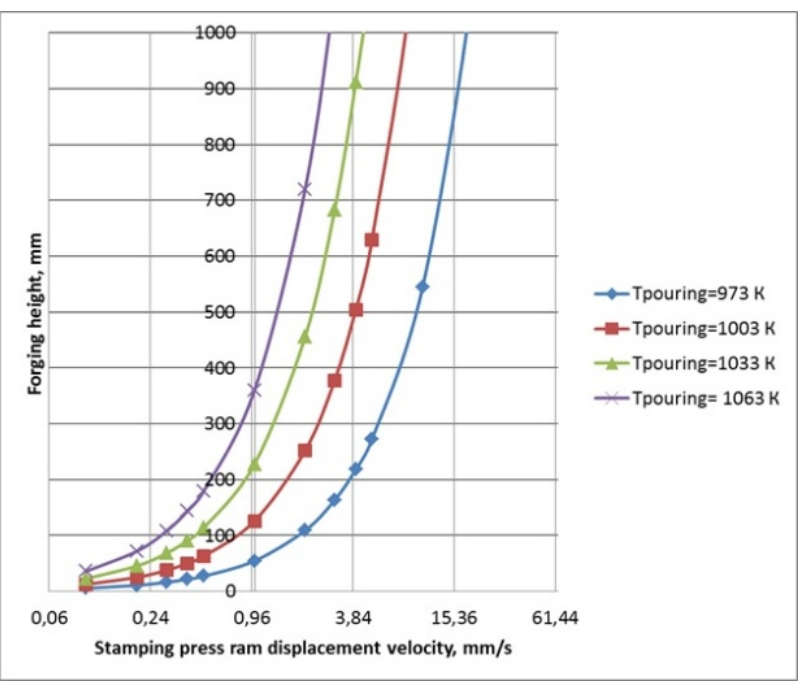

Fig. 5. Influence of the slider movement speed on the forging wall height at different filling temperatures

In the example, a forging with a wall height of 50 $\mathrm{mm}$ is used, the melt will rise to a height of this value before solidifying at a fill temperature of $973 \mathrm{~K}$, at a tool movement speed of $1 \mathrm{~mm} / \mathrm{s}$. According to Fig. 5, the speed of movement of the slider can be reduced while increasing the pouring temperature, and vice versa to increase the working speed of the press with a longer standing of the slider at the end of the stroke to ensure complete solidification of the metal before ejection of the forging.

Experimental studies were carried out to verify the adequacy of theoretical calculations and the choice of preferred technological parameters for manufacturing thin-walled axisymmetric forgings by the crystallizing metal stamping method. Stamping was performed on a hydraulic press model DB2432A with a nominal force of $1600 \mathrm{kN}$. The aluminum alloy was smelted in an electric crucible furnace PP50, with a maximum heating temperature of $1,373 \mathrm{~K}$. The melting time of $10 \mathrm{~kg}$ of charge was 1.5 hours.

\section{Conclusion}

The present study leads us to the following key conclusions:

1. Specific conditions of solidification of alloys in the temperature range with the formation of a two-phase zone are described by a mathematical model of solidification in relation to the technology of stamping metal crystallizing under pressure. The developed model was used to analyze the technological parameters of the process of liquid stamping of hollow thin-walled forgings made of AK7 casting alloy. The temperature and time parameters of the technological process of an aluminum alloy crystallizing under pressure were calculated, the control of which makes it possible to influence the process of solidification and formation of the structure of hollow thin-walled forgings.

2. The conducted experimental study confirmed the possibility of manufacturing hollow axisymmetric forgings with thin walls of the required height by stamping metal that crystallizes under pressure.

3. Control of theoretically justified technological parameters of the liquid stamping process allows for improved quality and uniformity of the structure of forgings made of AK7 alloy. When stamping other forgings that are similar in shape and size to the one under study, the process parameters can be recommended as a starting point, which, if necessary, are refined depending on the specific size, configuration and brand of the material.

This work was carried out using equipment provided by the Center of Collective Use of MSUT "STANKIN".

\section{References}

1. G.F. Balandin, Theory of casting forming (MSTU Publishers, Moscow, 1998)

2. H. Bayani, S.M.H. Mirbagheri, M. Barzegari, S. Firoozi, Journal of Materials Research and Technology, 3(1), 55-70 (2014)

3. I.Ya. Belousov, A.A. Saprykin, B.A. Sivak Proceedings of the conference "Week of metals in Moscow", 423-428 (2008) [in Russian]

4. G.S. Dmitrienko, L.A. Uvarova, Vestnik MSTU "Stankin", 1(19), 50-54 (2012) [in Russian]

5. L.G. Grishin, O.D. Solodukho, G.A. Ioffe, A.A. Saprykin, Forging and stamping production, 2, 4-6 (1996)

6. Yu.P. Kirdeev, I.Ya. Belousov, A.I. Rakogon Forging and stamping production, 3, 9-11 (2002)

7. S. Murali, M.S. Yong, Journal of Materials Processing Technology, 210(10), 1276-1281 (2010)

8. E.N. Sosenushkin, V.A. Kadymov, E.A. Yanovskaya, A.A. Tatarencev, A.E. Sosenushkin,, Key Engineering Materials, 684, 57-66 (2016) https://doi.org/10.4028/www.scientific.net/kem.684. 57

9. E.N. Sosenushkin, Progressive Processes of Bulk Stamping (Moscow: Mashinostroenie. 2011)

10. E.N. Sosenushkin, L.S. Frantsuzova, V.V. Grishin, Zagot. Proizv. Mashinostr., 5, 5-12 (2005) [in Russian]

11. E.N. Sosenushkin, Vestnik MSTU “Stankin”, 2, 1220 (2010) [in Russian]

12. E.N. Sosenushkin, A.V. Khromenkov, Yu.A. Melnik, Friction and wear, 35(6), 752-758 (2014)

13. E.N. Sosenushkin, E.A. Yanovskaya, K.N. Ivanov, T.A. Kinzhaev, non-Ferrous metals, 11(911), 83-88 (2018) [in Russian] 
14. E.N. Sosenushkin, L.S. Frantsuzova, E.A. Yanovskaya, T.A. Kinzhaev, Metallurg, 3, 2529 (2018) [in Russian]

15. V.N. Popov, A.A. Yushkanov, D.A. Ore, Vestnik MSTU "Stankin", 1(24), 98-102 (2012) [in Russian]

16. M.R. Portnoy, V.V. Kuzin, Vestnik MSTU "Stankin", 2(37), 21-26 (2016) [in Russian]

17. A.I. Veinik, Thermal Principles of the Theory of Casting (Mashgiz, Moscow, 1953) [in Russian] 